\title{
Longitudinal Study on Oral Health in Subjects with Alzheimer's Disease
}

\author{
Jonathan A. Ship, DMD and Scott A. Puckett, BS
}

Objective: To examine longitudinal oral health changes in unmedicated, generally healthy subjects with Alzheimer's disease (AD) and compare them to age- and gender-matched healthy, unmedicated control subjects.

Design: Oral health parameters were evaluated over 2 to 3 years and the results compared between subjects with $\mathrm{AD}$ and controls.

Setting: Clinical Center of the National Institutes of Health, Bethesda, Maryland.

Participants: Twenty-one community-dwelling subjects with a clinical diagnosis of AD and 21 age- and gender-matched control subjects. Neither population was being treated for any other systemic condition nor taking any prescription medications.

$\mathrm{A}^{\mathrm{s}}$ Izheimer's disease (AD) is the most common form of dementia among the elderly, accounting for about $50 \%$ to $60 \%$ of people with loss of cognitive function. ${ }^{1}$ The incidence of $\mathrm{AD}$ increases dramatically with age, from about $0.1 \%$ at age 60 to 65 to as high as $47 \%$ at age $85 .^{2}$ It is a degenerative neurological disorder characterized by progressive impairments in a wide range of cognitive abilities, from memory to abstract reasoning. ${ }^{3,4}$ Behavioral and functional symptoms often accompany the above-mentioned impairments, resulting in severe consequences to many organ systems. ${ }^{5}$

With the increasing percentage of the population over age 65, the number of individuals with Alzheimer's disease will also grow. Presently, there is no known effective treatment for the functional and intellectual degeneration resulting from the disease process. Most treatment efforts are generally care oriented, as opposed to cure oriented, and are directed to provide relief of physical, psychological, and emotional problems associated with the progressing disease. ${ }^{4}$

The oral cavity serves several essential functions (deglutition, host defense, and communication), yet frequently oral health is neglected in patients with terminal and incapacitating disorders. Although research advances have increased the understanding of $A D$, there are few reports of the effects of $A D$ and its progression on oral health. Previous cross-sectional studies have demonstrated diminished salivary gland function and altered gingival and dental health in unmedicated patients with $\mathrm{AD} .{ }^{5,6}$ Other reviews have recommended the establishment of early preventive and maintenance oral health regimens in patients with $\mathrm{AD}$ and other neurodegenerative disorders. ${ }^{4,10}$ To our

From the University of Michigan School of Dentistry, Ann Arbor, Michigan. Address correspondence to Jonathan A. Ship, DMD, Department of Oral Medicine, Pathology, and Surgery, University of Michigan School of Dentistry, 1011 N. University, Room 2010, Ann Arbor, MI 48109-1078.
Measurements: Unstimulated and stimulated major salivary gland flow rates were measured, and gingival, periodontal, dental, and oral mucosal tissues assessed.

Main Results: In general, subjects with AD demonstrated decreased salivary flow rates and diminished oral health, but most longitudinal changes in oral health status were not significantly different than controls.

Conclusions: Patients with AD are susceptible to a variety of oral health problems, and progression of AD can lead to a deterioration in oral health and function. These patients require aggressive preventive care to maintain function for as long as possible, which necessitates close cooperation among numerous health care professionals. J Am Geriatr Soc 42:57-63, 1994

knowledge, however, there have been no longitudinal studies published on oral health in patients with AD. These data would be useful to devise appropriate clinical recommendations for the maintenance of oral health and function in these patients and to preserve their quality of life for as long as possible. Accordingly, the purpose of this investigation was to examine longitudinal changes in salivary, gingival, periodontal, dental, and oral mucosal parameters in unmedicated, essentially healthy subjects with AD.

\section{MATERIALS AND METHODS}

Population Twenty-one community dwelling subjects in middle socio-economic status (13 men, 8 women) with a clinical diagnosis of AD were evaluated at the Clinical Center of the National Institutes of Health, Bethesda, Maryland, in a longitudinal study sponsored by the National Institute on Aging (Table 1). A diagnosis was made according to NINCDSADRDA criteria ${ }^{11}$ after subjects were screened vigorously to exclude other medical, neurological, and psychiatric conditions. All subjects were extensively evaluated with diagnostic radiographs, computed tomographic brain scans, magnetic resonance imaging, positron emission tomography, and neuropsychological and medical tests. ${ }^{12-15}$ No subject was taking any medication for systemic disease, nor being treated for any other disorder. The Mini-Mental State Examination (MMSE) $^{16}$ was administered to each subject at each visit to estimate the severity of cognitive impairment (Table 1). The interval between visits for subjects with $\mathrm{AD}$ was $23 \pm 11$ months (mean $\pm \mathrm{SD}$ ).

Twenty-one healthy subjects were selected as ageand gender-matched control subjects (Table 1). All were volunteer participants in a normative aging program conducted by the National Institute on Aging. These subjects were community dwelling, of middle socio-economic status, healthy, not being treated for 
TABLE 1. STUDY POPULATION*

\begin{tabular}{lccc} 
& $\begin{array}{c}\text { Control } \\
\text { Subjects } \\
(\boldsymbol{n}=\mathbf{2 1 )}\end{array}$ & $\begin{array}{c}\text { Alzheimer's } \\
\text { Subjects } \\
(\boldsymbol{n}=\mathbf{2 1})\end{array}$ & $\boldsymbol{P}^{* *}$ \\
\hline Men & 13 & 13 & \\
Women & 8 & 8 & \\
Age (y) & $65 \pm 12$ & $64 \pm 9$ & 0.0001 \\
Age (range) (y) & $48-90$ & $48-80$ & \\
Interval (mos) & $36 \pm 1.5$ & $23 \pm 11$ & 0.0001 \\
MMSE scoresf & & & \\
$\quad$ Visit 1 & $29.5 \pm 0.7$ & $18.9 \pm 5.5$ & 0.0001 \\
$\quad$ Visit 2 & $29.3 \pm 0.7$ & $12.2 \pm 9.2 \underline{\xi}$ & 0.0001 \\
\hline
\end{tabular}

* Values are expressed as mean $\pm S D$.

† Statistical comparison between control subjects and Alzheimer's subjects.

** Mini-mental state exam; Folstein et al. ${ }^{16}$

$\S$ Significantly lower than visit 1 MMSE scores for Alzheimer's $(P=0.0001)$

any systemic disease nor taking any prescription medications, and underwent rigorous medical, neurological, and laboratory screening. ${ }^{12,17}$ The interval between visits for control subjects was $36 \pm 1.5$ months (mean \pm SD) (Table 1).

Oral Health Parameters All study subjects received an interview and intraoral/extraoral clinical examination ${ }^{18,19}$ by one investigator (J.A.S.). The examiner was not blinded to the status of the study subject (AD vs control), but was unaware of the level of dementia among AD subjects at the time of examination. Major salivary gland flow rates were determined according to previously described criteria. ${ }^{5}$ All subjects refrained from eating, drinking, smoking, and oral hygiene for a minimum of 90 minutes before saliva collection. Unstimulated and stimulated saliva was collected from one parotid gland with the use of a modified Carlson-Crittenden cup as described previously. ${ }^{20}$ For any subject displaying no unstimulated parotid saliva production after 5 minutes, a retest was performed. Only after two negative unstimulated test results, plus positive evidence of a stimulated secretion, was a subject considered to have an unstimulated flow rate of zero. ${ }^{19}$ Submandibular saliva was collected from the orifice of Wharton's duct, as previously described. ${ }^{18}$ Salivary flow was stimulated by swabbing $2 \%$ citric acid on the dorsolateral surfaces of the tongue at 30 second intervals. ${ }^{18}$ After collection, the salivary volume was determined gravimetrically, assuming a specific gravity of 1.0. Submandibular saliva actually represents a combined submandibular/sublingual secretion due to the frequent common exit of the gland ducts, ${ }^{18,21}$ but will be referred to as submandibular saliva.

An examination of dental, gingival, periodontal, and oral mucosal tissues was performed on all subjects, according to previously described criteria. ${ }^{5}$ The number of teeth (excluding third molars), decayed-missingfilled-teeth score, and the number of teeth with cervical and coronal caries and restorations were recorded. ${ }^{22}$ The mesiobuccal, midbuccal, distobuccal, mesiolingual, midlingual, and distolingual surfaces of the six teeth proposed by Ramfjord ${ }^{23}$ were examined for periodontal parameters, ${ }^{24}$ according to National Institute of Dental Research criteria. ${ }^{22}$ Briefly, the 36 tooth surfaces were assessed for the presence or absence of dental plaque, gingival bleeding, and supra- or subgingival calculus. The distance from the free gingival margin to the cementoenamel junction and the distance from the free gingival margin to the bottom of the sulcus or pocket was measured with a National Institute of Dental Research color-coded periodontal probe. The percentage of tooth surfaces for each subject with dental plaque, gingival bleeding, and calculus was calculated and the amounts of gingival recession, pocketing, and level of attachment (LOA) were recorded. In addition, the extent and severity of LOA were determined according to criteria established by Carlos et al. ${ }^{25}$ All intraoral structures were assessed with a modified mucosal rating scale. ${ }^{26}$ Normal mucosal changes (dry, pale, or glossy mucosa and alterations in mucosal topography) were rated 0 , and any moderate or severe conditions (erythemic or leukoplakic lesions, ulcerations, and erosions) were rated $1 .^{26}$ Oral candidal lesions (atrophic, pseudomembranous, and denture stomatitis) were diagnosed clinically ${ }^{27}$ and grouped together with a rating of 1 .

Statistical analysis Intraexaminer replicate examinations for periodontal pocket depth $(S D=0.38 \mathrm{~mm})$ and LOA (SD $=0.42 \mathrm{~mm}$ ), and intraclass correlation coefficients for unstimulated submandibular flow rate $(0.978)$ and stimulated submandibular flow rate $(0.984)$ were calculated on nine control subjects. Data from the study were analyzed for differences between men and women within each group, and between subjects with $\mathrm{AD}$ and control subjects for each visit. The yearly change in each oral health parameter was determined: the change from the first to last visit for each subject was divided by the number of months between visits, and then multiplied by 12 months. A Student's $t$ test was used when mean values had a normal distribution, and a Mann-Whitney $U$ procedure was used for nonparametric values. $\chi^{2}$ and two-way Fisher's Exact tests were performed for prevalence data.

Correlation analyses were performed on subjects with $\mathrm{AD}$ to determine whether a relation existed between level of dementia (as determined from the MMSE score) at each visit and oral health parameters. Correlations were also determined on AD subjects for changes in dementia over time (change in MMSE score) and change in oral health parameters. To determine whether the relationship between age and change in oral health was different between groups, regressions were calculated for longitudinal change for each oral health parameter and age at baseline, and compared between the two groups. Data were analyzed using the RS1 software package (BBN Software Products Corp, Boston, MA). A criterion of $P<0.05$ was accepted for significance in all statistical tests.

\section{RESULTS}

Because no gender differences were observed for any of the clinical parameters in either AD or control populations, data for men and women were combined in all subsequent analyses. In addition, regression analyses for longitudinal changes in each oral health parameter and age at baseline were not statistically different between the two groups. 
Major salivary gland flow rates in AD and control groups at both visits are displayed in Figure 1. With the exception of stimulated parotid flow rates at visit 1 , subjects with $\mathrm{AD}$ had lower unstimulated and stimulated major salivary gland flow rates at both visits. Unstimulated $(P=0.02)$ and stimulated $(P=0.07)$ submandibular flow rates were lower in subjects with AD at visit 1 , and unstimulated parotid $(P=0.05)$ and stimulated submandibular $(P=0.05)$ flow rates were lower at visit 2 . Salivary flow rates increased over the time interval in control subjects, but were only significant for unstimulated parotid flow $(P=0.04)$. Unstimulated flow rates remained essentially stable in Alzheimer's subjects, whereas stimulated flow rates (parotid, $P=0.07$; submandibular, $P>0.05$ ) decreased over time.

The average yearly changes in unstimulated $(P=$ $0.06)$ and stimulated $(P=0.07)$ parotid flow rates tended to be lower in subjects with AD compared with control subjects (Table 2). There were no significant differences for average yearly changes for submandibular flow rates between the two groups. Analyses were performed to determine if there was a relation between MMSE scores and salivary gland flow rates. There were
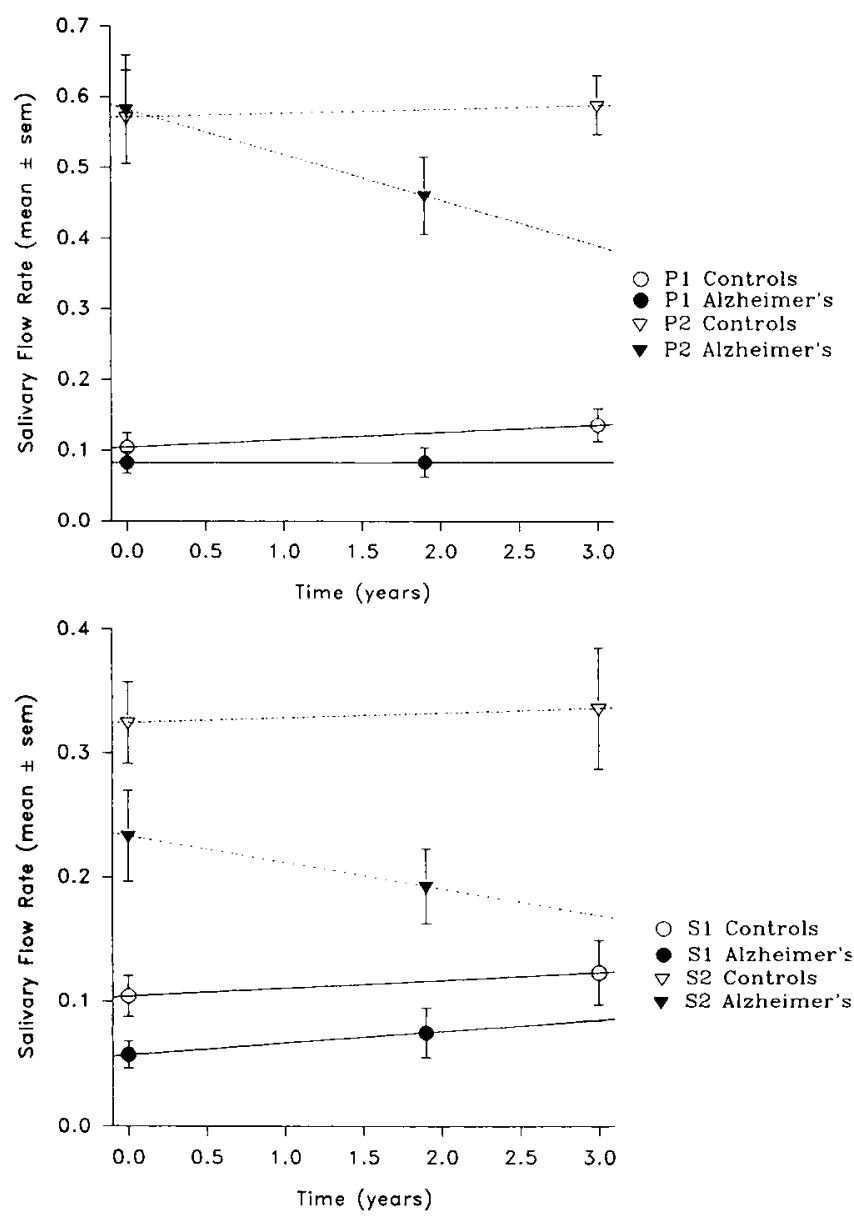

FIGURE 1. Longitudinal parotid (top panel) and submandibular (bottom panel) salivary gland flow rates in 21 unmedicated AD and 21 healthy control subjects. Results are expressed in milliliters per minute per gland (mean $\pm \mathrm{SE}$ ) for all flow rates. Values for AD subjects are extrapolated from the 1.9-year time point to the 3-year time point. P1 denotes unstimulated parotid flow, P2 stimulated parotid, S1 unstimulated submandibular, and S2 stimulated submandibular. positive correlations with submandibular flow rates but none for parotid flow rates. With decreasing MMSE scores, unstimulated submandibular (visit $1, r=0.42$, $P=0.05$; visit $2, r=0.47, P<0.05)$ and stimulated submandibular (visit $2, r=0.37, P=0.09$ ) flow rates diminished. However, there were no significant correlations between changes in salivary flow rates over the time period and changes in MMSE scores.

Gingival health parameters were consistently worse at both visits in subjects with AD compared with control subjects (Figure 2). This was significant for the percent of tooth surfaces with dental plaque (visit $1, P$ $=0.003$; visit $2, P=0.007$ ) and gingival bleeding (visit $2, P=0.0001)$. Gingival health in Alzheimer and control subjects worsened over time (with the exception of gingival bleeding in controls), but there were no statistical differences between the two groups (Table 2). For control subjects, percent plaque $(P=0.0001)$ and calculus $(P=0.001)$ increased over the interval between visits, whereas only calculus significantly increased for Alzheimer subjects $(P=0.003)$. In general, there were non-significant cross-sectional and longitudinal trends of poorer gingival health with lower MMSE scores, with two exceptions. With decreasing MMSE scores, the percent of dental surfaces with gingival bleeding (visit $1, r=-0.40, P=0.06$ ) and plaque (visit $2, r=-0.52, P=0.01$ ) increased.

No statistical differences were seen between control and $A D$ subjects for any of the periodontal parameters at visit 1 or at visit 2 . In general, periodontal health remained stable or improved slightly in both groups over the time span. Pocket depth decreased significantly over time in both control $(P=0.0001)$ and AD subjects $(P=0.004)$, but there were no longitudinal differences in the rate of decrease between the two groups. LOA improved from visit 1 to visit 2 for controls $(P=0.0001)$ but not for subjects with AD; however, these differences over time between both groups were not significant. The extent of teeth with LOA decreased significantly for controls $(P=0.02)$ and AD subjects $(P=0.006)$ over the time interval, and this improvement was greater in subjects with $\mathrm{AD}(P$ $=0.05)$. Furthermore, there were no significant correlations between MMSE scores and periodontal parameters.

The cross-sectional and longitudinal analysis of total number of remaining teeth and surfaces with coronal and cervical caries revealed no statistical differences between the two groups. The number of teeth with restored coronal (visit $1, P=0.006$; visit $2, P=0.03$ ) and cervical (visit $1, P=0.001$; visit $2, P=0.003$ ) surfaces was consistently higher in subjects with $A D$; however, the longitudinal changes were not significant for either population nor between groups (Figure 3). Decayed-missing-filled-teeth score levels in subjects with AD were significantly higher at visit $1(P=0.01)$ and visit $2(P=0.04)$, although there was no significant longitudinal change within either population or between the two groups (Table 2). The only dental parameter which was correlated significantly with MMSE scores was the number of teeth with decayed coronal surfaces. A negative correlation $(r=-0.40, P=0.06)$ was found at visit 2 between coronal decay and MMSE score. 
TABLE 2. 12-MONTH CHANGE IN ORAL HEALTH PARAMETERS*

\begin{tabular}{|c|c|c|c|c|c|}
\hline Parameter & $\begin{array}{l}\text { Control } \\
\text { Subjects }\end{array}$ & vs $0^{* *}$ & $\begin{array}{l}\text { Alzheimer's } \\
\text { Subjects }\end{array}$ & vs $0^{* * *}$ & Controls vs Alzheimer's\# \\
\hline \multicolumn{6}{|l|}{ Salivary $(\mathrm{ml} / \mathrm{min} \cdot$ gland $)$} \\
\hline Unstimulated parotid & 0.010 & 0.04 & 0.006 & NS & 0.06 \\
\hline Stimulated parotid & 0.003 & NS & -0.045 & 0.07 & 0.07 \\
\hline Unstim submandibular & 0.007 & NS & 0.020 & NS & NS \\
\hline Stim submandibular & 0.004 & NS & -0.027 & NS & NS \\
\hline \multicolumn{6}{|l|}{ Gingival (\%) } \\
\hline Dental plaque & 2.90 & 0.0001 & 0.47 & NS & NS \\
\hline Bleeding & -0.72 & NS & 2.69 & NS & NS \\
\hline Calculus & 3.94 & 0.001 & 6.20 & 0.003 & NS \\
\hline \multicolumn{6}{|l|}{ Peridontal (mm) } \\
\hline Pocket depth & -0.139 & 0.001 & -0.126 & 0.004 & NS \\
\hline Recession & 0.006 & NS & -0.003 & NS & NS \\
\hline LOA\#\# & -0.095 & 0.001 & -0.226 & NS & NS \\
\hline Extent LOA (\%) & -1.99 & 0.02 & -6.24 & 0.006 & 0.05 \\
\hline Severity LOA & -0.009 & NS & -0.04 & NS & NS \\
\hline \multicolumn{6}{|l|}{ Dental } \\
\hline Number of teeth & -0.407 & NS & -0.243 & NS & NS \\
\hline DMFT\#\#\# & 0.461 & NS & 0.347 & NS & NS \\
\hline Decayed coronal & 0.112 & NS & 0.050 & NS & NS \\
\hline Decayed cervical & -0.201 & NS & -0.027 & NS & NS \\
\hline Restored coronal & -0.003 & NS & -0.066 & NS & NS \\
\hline Restored cervical & 0.000 & NS & 0.001 & NS & NS \\
\hline
\end{tabular}

- Negative values denote a decrease over time, positive values denote an increase over time.

** P values for statistical comparison of control values versus no change from baseline (0).

*** P values for statistical comparison of Alzheimer values versus no change from baseline (0).

\# P values for statistical comparison of control and Alzheimer values.

\#\# Level of attachment.

\#\#\# Decayed-missing-filled-teeth score.

Intraoral mucosal examination showed no significant differences between control and $A D$ groups at either visit. In addition, there were no significant changes in oral mucosal health over time within or between the two groups. Control (visits 1 and $2,43 \%$ ) and AD (visit $1,40 \%$; visit $2,67 \%$ ) subjects with removable prostheses (full or partial dentures) were more likely to have clinically detectable alterations in oral mucosa. There was a significant negative correlation between MMSE scores and oral mucosal health among denture-wearing AD subjects (visit 2, $r=-0.97, P<0.01$ ), but not among non-denture-wearing subjects. The longitudinal analysis revealed that decreasing MMSE scores were correlated with diminished mucosal health for denture-wearing $(r=-0.62, P<0.01)$ and non-denture-wearing ( $r=-0.43, P=0.06)$ AD subjects.

\section{DISCUSSION}

The results of this study demonstrate significant differences in the oral health of unmedicated subjects with Alzheimer's disease compared to age- and gendermatched healthy, non-demented control subjects. In general, these differences were observed in both crosssectional analyses, but not confirmed in the relatively short (2 to 3 years) longitudinal span of the study. Specifically, salivary gland flow rates (especially submandibular) were consistently lower in subjects with AD. There was a greater history of dental disease (increased dental restorations), more gingival disease, but indistinguishable periodontal conditions in subjects with $\mathrm{AD}$ compared with controls subjects. Oral mucosal health was not different for the two groups; however, denture-wearing subjects in both groups showed altered mucosal health.

These cross-sectional results are consistent with previously reported findings of altered salivary gland function, gingival health, and differences in dental findings using a similar population of subjects who were essentially healthy except for AD., 6 However, our longitudinal results overall did not reflect the crosssectional findings. Whereas stimulated salivary gland flow rates decreased and gingival health and overall dental disease worsened over the 2 to 3 years in subjects with $A D$, the remaining oral health parameters remained essentially stable. Nevertheless, many of the oral health parameters examined indicated consistently greater impairment among subjects with AD. Analyses of rate of change in these parameters (Figures 1 to 3 ) suggest that oral diseases will significantly impact on a person's systemic health and quality of life sooner in subjects with $\mathrm{AD}$ compared with control subjects. Furthermore, it can be expected that these subjects with AD will be treated eventually for medical conditions concomitant with the progression of $\mathrm{AD}$ and be prescribed medications, many of which can have deleterious consequences to oral health. ${ }^{28}$

Some form of oral hygiene was performed in the AD subjects in this study because not all dental surfaces 

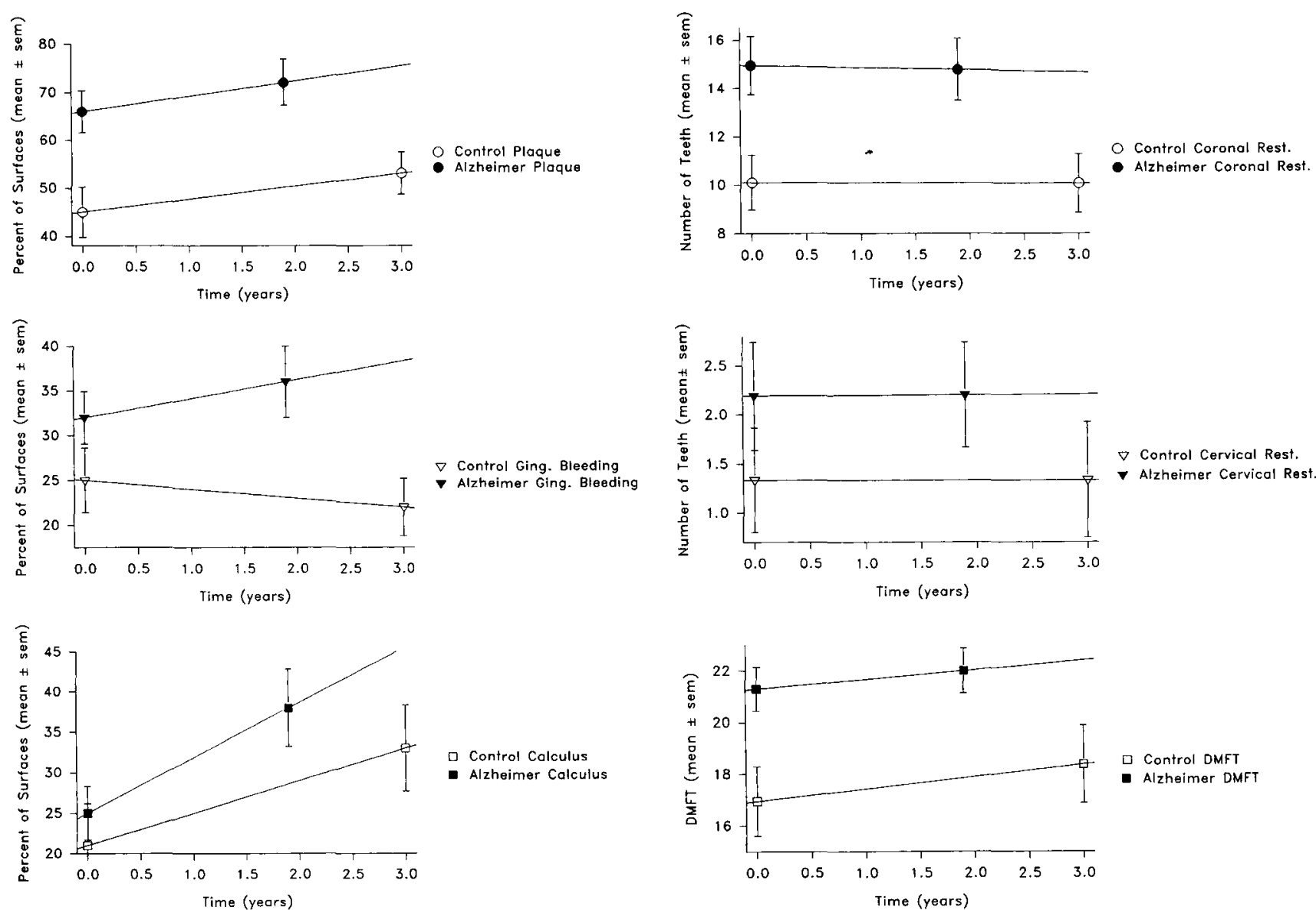

FIGURE 2. Longitudinal gingival parameters in 21 unmedicated $A D$ and 21 healthy control subjects. Gingival results are expressed as percent of tooth surfaces examined with dental plaque (top panel), gingival bleeding (middle panel), and calculus (bottom panel; mean $\pm \mathrm{SE}$ ). Values for AD subjects are extrapolated from the 1.9-year time point to the 3-year time point.

were covered by dental plaque or had gingival bleeding (Figure 2). Oral hygiene tasks, however, will probably undergo significant change in the course of the disease. These subjects were also community dwelling; the extent of oral health care received by institutionalized persons is generally lower and less frequent compared to care received by subjects in this study. It can be hypothesized that oral conditions of institutionalized patients with $\mathrm{AD}$ and other medical problems, taking numerous prescription medications, will deteriorate more rapidly due to inadequate oral health care. Therefore, the findings in this study of altered oral health in community-dwelling, unmedicated subjects with early $\mathrm{AD}$ may underestimate the eventual progression of oral disease and impairment.

Saliva is essential for the maintenance of a healthy oral environment, and diminished output may predispose a person to multiple oral and systemic problems. ${ }^{29}$ For example, diminished salivary function can predispose a person to aspiration pneumonia. ${ }^{30}$ Major salivary gland flow rates were consistently lower (with the exception of stimulated parotid at visit 1 ), and stimulated function diminished over time in subjects with $\mathrm{AD}$ (Figure 1). These negative trends could be acceler-

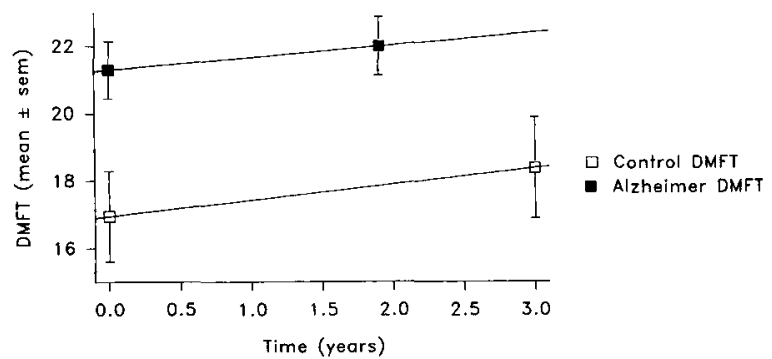

FIGURE 3. Longitudinal dental parameters in 21 unmedicated AD and 21 healthy control subjects. Results are expressed as number of teeth with coronal restorations (top panel), number of teeth with cervical restorations (middle panel), and the decayed-missing-filledteeth score (DMFT) (bottom panel; mean $\pm \mathrm{SE}$ ). Values for $\mathrm{AD}$ subjects are extrapolated from the 1.9-year time point to the 3-year time point.

ated if patients receive psychotropic or other anticholinergic drugs, which are frequently associated with decreased salivary function. ${ }^{31}$

The mechanisms underlying the diminished salivary gland function in $\mathrm{AD}$ subjects are unclear. Secretion by these glands is stimulated by activity of the salivatory nuclei and is controlled by sympathetic and parasympathetic innervation. Parasympathetic stimulation increases the volume of saliva secreted, whereas sympathetic stimulation has greater effects on salivary composition and protein content. ${ }^{32}$ The superior and inferior salivatory nuclei are located within the reticular formation near the pontomedullary junction of the brainstem and are in close proximity to the solitary nucleus, which receives input from afferent taste fibers. ${ }^{33,34}$ The salivatory nuclei receive innervation from the corticoreticular tract, projecting from higher cortical regions, ${ }^{35}$ which in turn receive most of their cholinergic innervation from the nucleus basalis. ${ }^{35}$ It is known that degeneration of the cholinergic system ${ }^{33,36-42}$ and the nucleus basalis occurs in $A D, 3,36$ which could lead to the inhibition of stimulus transduction to lower levels of the brainstem, including the salivatory and 
solitary nuclei. It is interesting to note that changes in salivary output over time in subjects with $A D$ were more dramatic for citrate-stimulated compared with unstimulated secretions (Table 2), which could partially be due to concomitant alterations in gustatory function. ${ }^{43}$ Furthermore, there have been reports of brainstem degeneration, even within the reticular formation, ${ }^{44}$ in patients with AD. These findings, however, are not consistent within an individual and between persons with $\mathrm{AD}, 45,46$ and the heterogeneity of clinical findings in these patients has been documented. ${ }^{47}$ Therefore, the variable pattern of neuropathological destruction could account for the variety of salivary gland findings in these individuals.

The gingival health of $\mathrm{AD}$ subjects was considerably worse than that of control subjects and deteriorated with increased severity of dementia. Extrapolation of dental plaque findings in subjects with $A D$ indicates that three-quarters of all tooth surfaces will be covered with plaque 3 years from baseline (Figure 2). Less attention is devoted to appearance and hygiene in patients with early $\mathrm{AD}^{48}$ and with the concomitant decline in cognitive function, gingival health will probably continue to deteriorate. Gingivitis could eventually have systemic implications and predispose a person to aspiration pneumonia. ${ }^{49}$ In contrast to the gingival findings, the periodontal results demonstrated no significant differences between subjects with $A D$ and controls. The six index teeth used in this study ${ }^{23}$ have been shown to provide an accurate indication of gingival health, ${ }^{50}$ but they may underestimate periodontal disease progression. ${ }^{51}$ Perhaps the 2- to 3-year span of the study was insufficient for gingivitis to increase periodontitis markedly. Furthermore, there is evidence to suggest that gingivitis may not necessarily be a forerunner of periodontal diseases. ${ }^{52-55}$ Nevertheless, the deterioration in gingival health eventually may lead to significant periodontal destruction and tooth loss.

Dental conditions did not significantly worsen in subjects with $\mathrm{AD}$ over the 2- to 3-year interval, yet there was a consistently higher history of dental disease among subjects with $A D$, as shown by higher decayedmissing-filled-teeth scores and greater numbers of teeth with restored coronal and cervical surfaces (Figure 3). The results also demonstrate that despite a greater dental disease history, subjects with $\mathrm{AD}$ were receiving dental care. It can be speculated, however, that as cognitive and motor function deteriorate, and these patients eventually become more impaired, they will probably be less likely to perform regular oral hygiene and seek dental treatment. Furthermore, the risk for developing new or recurrent dental caries is greatly increased in these patients because of diminished salivary gland output. It is unknown to what magnitude dental caries must extend to produce an abscess, bacteremia, or septicemia. Nevertheless, subjects with $A D$ have experienced a greater amount of dental diseases compared with control subjects, despite similar geographical and socio-economic backgrounds. With a concomitant decrease in salivary gland function, they are at an increased risk for developing caries and its sequelae.
The overall condition of oral mucosal tissues was similar between Alzheimer's subjects and control subjects throughout the study. For both subject groups, the denture-wearing subjects were more likely to demonstrate clinical alterations in oral mucosa, which is consistent with previous reports. ${ }^{56,57}$ The presence of removable prostheses, rather than the diagnosis of $A D$, is probably a greater prognosticator for oral mucosal disorders. A general trend was seen for decreased cognition and increased oral mucosal problems, which indicates the need for care providers to remove patient's dentures at bedtime and to encourage routine oral home care.

Preventive and treatment goals for individuals with $\mathrm{AD}$ are to preserve and maintain oral health and function for as long as possible. ${ }^{7-10}$ Manual or mechanical toothbrushing and flossing should be performed at least daily and preferably after each meal, and dentures should be cleaned and removed every night. Health care providers, relatives, and friends should assist in these measures if necessary, and can help identify new problems necessitating appropriate consultation. Fluoridated dentifrices, water supplies, mouth rinses, and topical gels are required to prevent dental caries, especially in patients with diminished salivary output. These patients should also be encouraged to use sugarless candies, chewing gums and artificial salivas, and should be monitored for oral fungal infections. Finally, as long as a patient is able to cooperate during routine dental treatment, frequent recall visits to dental professionals are necessary to assist in the prevention of oral disease and to detect and treat problems before function is impaired.

Recommendations for optimum oral health care in patients with AD include the necessity of establishing relationships among dentists, dental hygienists, physicians, nursing staff and other care-providers, as well as family members and appropriate friends involved in the regular care of the patient. This may increase the likelihood of integrating daily oral health care into other services provided by care-givers in communitydwelling patients, or subjects residing in long-term care facilities. The multidisciplinary approach to care of all patients with dementia will assist both patients and care-providers in the assessment of functional needs and treatment goals.

A scientific account of the process of aging requires a systematic approach to the role of disease in the explanation. ${ }^{58}$ Therefore, more extensive longitudinal studies involving subjects with well characterized diseases are necessary to identify patients at risk for oral diseases, to anticipate diagnostic and management needs of the elderly, and to implement effective regimens to prevent the development of oral problems. ${ }^{99}$

\section{ACKNOWLEDGMENTS}

We acknowledge the contributions of Dr Bruce Baum (National Institute of Dental Research, NIH) for research guidance at the NIH, and Dr Mark Supiano (University of Michigan School of Medicine) and Dr Jed Jacobson (University of Michigan School of Dentistry) for critical review of the manuscript. We are 
indebted to the assistance of the National Institute on Aging staff, control subjects, and subjects with Alzheimer's disease for their cooperation.

\section{REFERENCES}

1. Katzman R. Medical progress: Alzheimer's disease. N Engl J Med 1986:315:964-973

2. Evans DA, Funkerstein H, Albert MS et al. Prevalence of Alzheimer's disease in a community population of older persons. JAMA 1989;262:2551-2556

3. Montelaro S. Alzheimer's disease: A growing concern in geriatric dentistry. Gen Dent 1985;Nov-Dec:494-497.

4. Fabiszewski KJ. Caring for the Alzheimer's patient. Gerodontology 1987;6:53-58.

5. Ship JA. Oral health of patients with Alzheimer's disease. J Am Dent Assoc 1992;123:53-58.

6. Ship JA, DeCarli C, Friedland RP, Baum BJ. Diminished submandibular salivary flow in dementia of the Alzheimer type. J Gerontol 1990;45:M61 66.

7. Niessen LC, Jones IA, Zocchi M, Gurian B. Dental care for the Alzheimer's patient. J Am Dent Assoc 1985;110:207-209.

8. Niessen LC, Jones JA. Alzheimer's disease: A guide for dental profession als. Spec Care Dent 1986;6:6-12.

9. Niessen LC, Jones JA. Oral health and the patient with dementia. Spec Care Dent 1987:7:36-38

10. Niessen LC, Jones JA. Professional dental care for patients with dementia. Gerodontology 1987;6:67-71.

11. McKhann G, Drachman D, Folstein J et al. Clinical diagnosis of Alzheimer's disease: Report of the NINCDS-ADRDA work group under the auspices of Department of Health and Human Services Task Force on Alzheimer's disease. Neurology 1984;3:939-944.

12. Duara R, Grady CL, Haxby JV et al. Human brain glucose utilization and cognitive function in relation to age. Ann Neurol 1984;16:702-717.

13. Duara R, Grady CL, Haxby JV et al. Positron emission tomography in Alzheimer's disease. Neurology 1986;36:879-887.

14. Koss E, Weiffenbach JM, Haxby JV, Friedland RP. Olfactory detection and identification performance are dissociated in early Alzheimer's disease. Neurology 1988;38:1228-1232.

15. Schapiro MB, Haxby JV, Grady CL, Rapoport SI. Topographical comparison of lesions in Trisomy 21 and Alzheimer's disease: a study with PET, anatomical and neuropathological investigations. In: Rapoport SR, Petit $\mathrm{H}$, Leys $\mathrm{H}$, Christen Y, eds. Imaging, Cerebral Topography and Alzheimer's Disease. Berlin: Springer Verlag 1990, pp 97-107.

16. Folstein MF, Folstein SE, McHugh PR. "Mini-mental state": A practical method for grading the cognitive state of patients for the clinician. J Psychiatr Res $1975 ; 12: 189-198$.

17. Duara R, Margolin RA, Robertson-Tchabo EA et al. Cerebral glucose utilization, as measured with positron emission tomography in 21 healthy men between the ages of 21 and 83 years. Brain 1983;106:761-775.

18. Fox PC, Van der Ven PF, Sonies BC et al. Xerostomia: Evaluation of a symptom with increasing significance. J Am Dent Assoc 1985;110:519525.

19. Ship JA, Fox PC, Baum BJ. How much saliva is enough? Normal function defined. J Am Dent Assoc 1991;122:63-69.

20. Baum BJ. Evaluation of stimulated parotid saliva flow rate in different age groups. J Dent Res 1981;60:1292-1296.

21. Goss CM (ed). Gray's Anatomy, 29th American ed. Philadelphia: Lea \& Febiger, 1973, pp 1188-1190.

22. US Department of Health and Human Services. Oral health of United States adults. NIH publication no. 87-2868. National Institutes of Health, Public Health Service, 1987.

23. Ramfjord SP. Indices for prevalence and incidence of periodontal disease. J Periodontol 1959;7:51-59.

24. Ship JA, Wolff A. Gingival and periodontal parameters in a population of healthy adults, 22-90 years of age. Gerodontology 1988;7:55-60.

25. Carlos J, Wolfe M, Kingman A. The extent and severity index: A simple method for use in epidemiologic studies of periodontal disease. J Clin Periodontol 1986;13:500-504.

26. Wolff A, Ship JA, Tylenda CA et al. Oral mucosal appearance is unchanged in healthy, different-aged individuals. Oral Surg Oral Med Oral Pathol 1991;71:569-572.

27. Wood NK, Goaz PW. Differential Diagnosis of Oral Lesions. St Louis: Mosby-Year Book, 1991

28. Ship JA. Oral sequelae of common geriatric diseases, disorders, and impairments. Clin Geriatr Med 1992;8:483-497.

29. Mandel ID. The role of saliva in maintaining oral homeostasis. J Am Dent Assoc 1989:119:298-304

30. Gibson G, Barrett E. The role of salivary function on oropharyngeal colonization. Spec Care Dent 1992;12:153-156

31. Sreebny LM, Schwartz SS. A reference guide to drugs and dry mouth. Gerodontology 1986;5:75-99.

32. Baum BI. Neurotransmitter control of secretion. J Dent Res 1987;66:628 632

33. Gilman S, Newman SW. Manter and Gatz's Essentials of Clinical Neuro anatomy and Neurophysiology, 8th ed. Philadelphia: F.A. Davis Co, 1992

34. Carpenter MB, Sutin J. Human Neuroanatomy, 8th ed. Baltimore: Williams \& Wilkins, 1983

35. Carpenter MB. Core Text of Neuroanatomy, 4th ed. Baltimore: Williams \& Wilkins, 1991

36. Coyle JT, Price DL, Delong MR. Alzheimer's disease: A disorder of cortical cholinergic innervation. Science 1983;219:1184-1190.

37. Greenwald BS, Mohs RC, Davis KL. Neurotransmitter deficits in $\mathrm{Alz}$ heimer's disease: Criteria for significance. J Am Geriat Soc 1983;31:310314.

38. Marchbanks RM. Biochemistry of Alzheimer's disease. J Neurochem 1982;39:9-14.

39. Growdon $\mathrm{JH}$. Neuropharmacology of degenerative diseases associated with aging. Med Res Rev 1983;3:253-257.

40. Giacobini E. The cholinergic system in Alzheimer's disease. Prog Brain Res 1990;84:321-332.

41. Arendt T, Taubert G, Bigl V, Arendt A. Amyloid deposition in the nucleus basalis of Meynert complex: A topographic marker for degenerating cell clusters in Aizheimer's disease. Acta Neuropathol 1988;75:226-232.

42. Araujo DM, Lapchak PA, Robitaille $Y$ et al. Differential alteration of various cholinergic markers in cortical and subcortical regions of human brain in Alzheimer's disease. J Neurochem 1988;50:1914-1923.

43. Schiffman SS, Clark CM, Warwick ZS. Gustatory and olfactory dysfunction in dementia: Not specific to Alzheimer's disease. Neurobiol Aging 1990;11:597-600.

44. Iseki $\mathrm{E}$, Matsushita $\mathrm{M}$, Kosaka $\mathrm{K}$ et al. Distribution and morphology of brain stem plaques in Alzheimer's disease. Acta Neuropathol 1989;78:131136.

45. Hansen LA Masliah E Terry RD, Mirra SS A neuropathological subset of Alzheimer's disease with concomitant Lewy body disease and spongiform change. Acta Neuropathol 1989;78:194-201.

46. Braak $H$, Braak E. Neuropathological staging of Alzheimer-related changes. Acta Neuropathol 1991;82:239-259.

47. Blennow $K$, Wallin A. Clinical heterogeneity of probable Alzheimer's disease. J Geriatr Psychiatry Neurol 1992;5:106-113.

48. Besdine R et al. Handbook of Geriatric Care. New Jersey: Sandoz Corp, 1982, pp 47-56.

49. Bartlett JG, Gorbach SL, Finegold SM. The bacteriology of aspiration pneumonia. Am I Med 1974;56:202-206.

50. Fleiss JL, Park MH, Chilton NW et al. Representativeness of the "Ramfjord teeth" for epidemiologic studies of gingivitis and periodontitis. Commun Dent Oral Epidemiol 1987;15:221-224.

51. Rams TE, Oler J, Listgarten MA, Slots J. Utility of Ramfjord index teeth to assess periodontal disease progression in Iongitudinal studies. J Clin Periodontol 1993;20:147-150.

52. Goodson JM, Tanner ACR, Haffajee AD et al. Patterns of progression and regression of advanced periodontal disease. J Clin Periodontol 1982;9:472481

53. Goodson JM, Haffajee AD, Socransky SS. The relationship between attachment level loss and alveolar bone loss. J Clin Periodontol 1984;11:348369.

54. Haffajee AD, Socransky SS, Goodson IM. Clinical parameters as predictors of destructive periodontal disease activity. J Clin Periodontol 1983;10:257265 .

55. Socransky SS, Haffajee AD, Goodson JM, Lindhe J. New concepts of destructive periodontal disease. I Clin Periodontol 1984;11:21-32.

56. Budtz-Jorgensen E. Oral mucosal lesions associated with the wearing of removable dentures. J Oral Pathol 1981;10:65-80.

57. Watson IB, MacDonald DG. Oral mucosa and complete dentures. J Prosthet Dent 1982;47:133-140.

58. Fozard JL, Metter EJ, Brant LJ. Next steps on describing aging and disease in longitudinal studies. J Gerontol 1990;45:116-127.

59. Baum BJ, Ship JA, Wu AJ. Salivary gland function and aging: a model for studying the interaction of aging and systemic disease. Crit Rev Oral Biol Med 1992;4:53-64. 